\title{
Hydraulic System Device
}

National Cancer Institute

\section{Source}

National Cancer Institute. Hydraulic System Device. NCI Thesaurus. Code C50312.

A system designed to use fluid pressure to bring about movement. 